\title{
An Introduction to Birdsong and the Avian Song System
}

\author{
Eliot A. Brenowitz, ${ }^{1}$ Daniel Margoliash, ${ }^{2}$ Kathy W. Nordeen ${ }^{3}$ \\ ${ }^{1}$ Departments of Psychology and Zoology, Box 351525, University of Washington, Seattle, \\ Washington 98195 \\ ${ }^{2}$ Department of Organismal Biology and Anatomy, University of Chicago, Chicago, Illinois 60637 \\ ${ }^{3}$ Department of Brain and Cognitive Sciences, University of Rochester, Rochester, New York 14627
}

\section{INTRODUCTION}

This special issue of the Journal of Neurobiology is devoted to a consideration of the avian song control system. In the 20 years that have passed since Nottebohm et al. (1976) first identified forebrain circuits that control song in birds, the song system has emerged as a leading model in behavioral neuroscience. To mark the beginning of the third decade of study of this model, we invited several leading investigators to contribute to this volume. We set two goals for the authors: to review progress in their area of study and, more important, to identify critical directions for future research.

The modern study of birdsong began with the work of William Thorpe $(1958,1961)$. He showed that chaffinches (Fringilla coelebs) collected as nestlings and reared in the laboratory in isolation from conspecific adult males produced very abnormal songs. If these young birds were exposed to tape recordings of wild chaffinch songs, however, they eventually produced normal songs that matched those heard on the recordings. These studies demonstrated for the first time that young birds must learn the song of their species by listening to adult conspecifics. Thorpe's student Peter Marler greatly expanded upon this early work. Marler and his colleagues demonstrated the existence of local geographic song "dialects," that song learning is characterized by early sensitive periods, and that birds have innate predispositions to learn the song of their species. Masakazu

Correspondence to: E. A. Brenowitz (C) 1997 John Wiley \& Sons, Inc. CCC 0022-3034/97/050495-06
Konishi, while a student with Marler, showed that birds must be able to hear themselves sing to develop song normally. Fernando Nottebohm, also while a student with Marler, showed that the peripheral control of song production is lateralized. Nottebohm and his colleagues subsequently identified neural circuits in the avian forebrain that control song behavior. This important discovery paved the way for many investigators who have subsequently contributed to our understanding of song behavior and its neural control.

The birdsong system offers several advantages as a model for identifying neural mechanisms that underlie biologically relevant behavior:

1. Song is a learned behavior that is controlled by discrete neural circuits.

2. There are distinct phases in the development of song, with well-defined sensitive periods. One can relate the ontogeny of song behavior to the development of the underlying neural circuits.

3. Song is the product of stereotyped motor programs, with hierarchical organization of the premotor and motor nuclei.

4. Song behavior and the associated neural circuits are sexually dimorphic in most species.

5. Gonadal steroid hormones have pronounced effects on the development and adult function of the song control circuits, as well as on song behavior.

6. There is extensive plasticity of the adult song system, including ongoing neurogenesis and seasonal changes in morphology.

7. There is pronounced species diversity in different aspects of song behavior, including the timing of vocal learning, sex patterns of song 
production, number of songs that are learned, and seasonality of song behavior. This diversity provides opportunities for comparative studies of the song control system.

\section{GENERAL CHARACTERISTICS OF SONG BEHAVIOR}

In most bird species, song is produced only by males. Females also sing, however, in numerous species, and there is much taxonomic diversity in the complexity of female song relative to that of conspecific males. Song in females reaches its ultimate performance in certain tropical species in which the male and female contribute equally to vocal duets (Morton, 1996).

Song serves two main functions in birds (Catchpole and Slater, 1995; Kroodsma and Miller, 1996). In many species, song is used to declare a territory from which other birds are aggressively excluded. Muting birds decreases their ability to deter intrusions by other birds. Both males and females may use song in this context. Song may also be used by males to attract females to mate with them, as well as to stimulate the females' reproductive behavior and physiology. In temperate-zone bird species, song used in either the territorial or mating contexts is produced at higher rates during the breeding season, and at lower rates or not at all outside the breeding season. In bird species residing in the tropics, song is often used for territorial defense throughout the year.

Bird songs have well-defined acoustic structures that are characteristic of each species. There is extreme diversity in the types of sounds that birds produce and the syntactical arrangements of those sounds. Figure 1 presents a sampler of song structures in several species, as visualized in sound spectrograms. The different structural components of song can be described in order of increasing complexity. The simplest individual sounds that birds produce are referred to as song "elements" or "notes." A series of one or more elements that occur together in a regular pattern in song is referred to as a song "syllable." A sequence of one or more syllables that occurs repeatedly in song is described equivalently as either a song "phrase" or "motif." A particular combination of phrases or motifs that occurs repeatedly constitutes a song "type." Finally, a sequence of one or more phrases separated from other phrase sequences by silent intervals of variable duration is a song "bout."

\section{GENERAL CHARACTERISTICS OF SONG DEVELOPMENT}

As Thorpe and Marler showed, song is a learned behavior. There are distinct phases to song development (Marler, 1997). During an initial memorization phase, young birds acquire a sensory model of song by listening to adult conspecifics sing. This first stage of song development is often called "memory acquisition" or "sensory acquisition." At some later time, juvenile birds begin to convert this sensory memory to a motor pattern of song production in the sensorimotor phase of song learning. There are three stages in the sensorimotor phase. Initially, birds produce subsong, which is quiet, crudely structured, and quite variable in form. With further vocal practice, young birds progress to plastic song, which is louder and better structured, but still variable in form. Finally, song becomes crystallized in structure as the birds produce a stereotyped version of the sensory model to which they were exposed earlier. Song crystallization requires the presence of circulating testosterone $(\mathrm{T})$; song memorization, subsong, and plastic song can occur in the absence of $\mathrm{T}$ (reviewed by Bottjer and Johnson, 1997; Schlinger, 1997). The specific age at which these different phases of song development occur varies considerably between species.

As with other aspects of song behavior, there is great species diversity in the timing of song development. At one extreme are species referred to as age-limited or sensitive period learners, in which song memorization is limited to the first year of life and new songs are not acquired in adulthood (Marler and Peters, 1987). Examples of age-limited learners include the zebra finch (Taeniopygia guttata) and white-crowned sparrow (Zonotrichia leucophrys). At the other extreme are species in which new song patterns can be developed beyond the first year of life; such species are referred to as open-ended learners. Examples include the canary (Serinus canaria) and European starling (Sturnus vulgaris). The development of new songs by adults of open-ended species generally occurs in a restricted seasonal manner, rather than continuously throughout the year (but see Bohner et al., 1990). It is not clear whether the ability to learn new songs continues throughout the entire adulthood of open-ended species, or the extent to which such adult learning involves the acquisition of new sensory memories rather than the production of sensory models acquired earlier in life (but see Chaiken et al., 1994). Many other species have developmental 

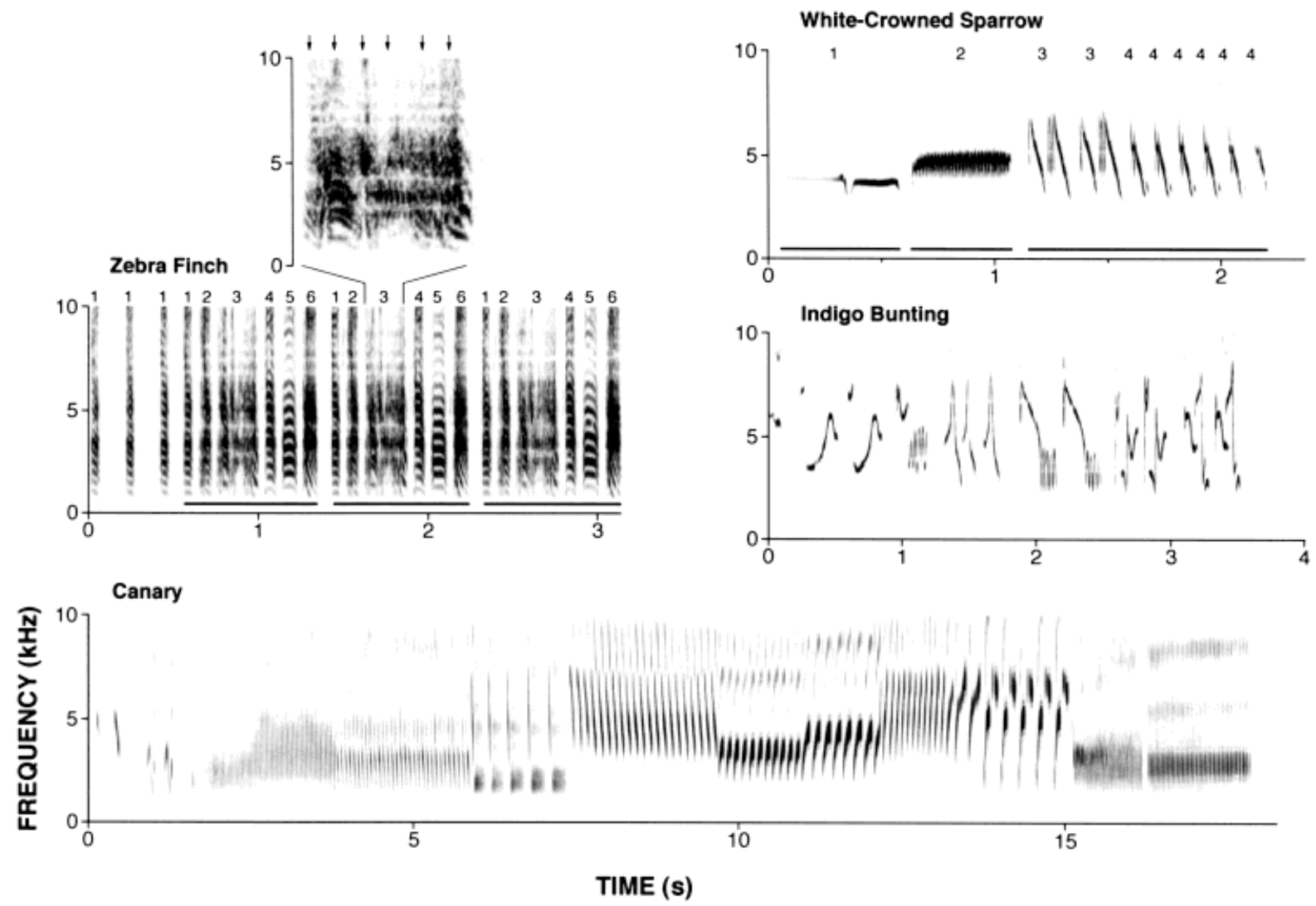

Figure 1 Examples of bird songs from four species. Bird songs are commonly viewed as sound spectrographs, frequency versus time representations. The intensity of the sound is represented by the grayscale. The four species shown are common model systems and suggest the variation in temporal and spectral properties seen in songs. The zebra finch is the most popular model system for neurobiologists. The song starts with introductory notes ( see text for discussion of song terminology) and is organized into a motif which can be repeated several times (dark bars). Each motif consists of a sequence of syllables, which are identified by the numbers above the spectrograph. Syllables can contain one or more notes (or elements). For example, the syllable shown at higher resolution has six notes (denoted by arrows). Each note and syllable has a spectrally complex pattern, with either broadband or harmonic structure. The white-crowned sparrow and indigo bunting songs are spectrally simpler and illustrate different temporal patterns. For the white-crowned sparrow song, phrases (dark bars) and syllables (numbers) are marked. The song types of the former three species are relatively discrete and short. In contrast, the canary sings continuously for long periods of time. The song consists of a series of phrases, with each phrase having one or two syllables repeated multiple times.

patterns of song learning that fall between the extremes of age-limited and open-ended learning.

\section{AUDITORY INPUT AND FEEDBACK ARE NECESSARY FOR SONG LEARNING AND MAINTENANCE}

Juvenile birds will not develop normal song behavior if they do not hear the song of conspecific adults from either tape recordings or a live tutor. Young birds must then be able to hear themselves sing to develop a crystallized version of the conspecific song model acquired during the earlier memorization phase. As first shown by Konishi (1965a,b), if juvenile birds are deafened after the memorization phase but before song crystallization, they will not develop normal song. Translating the memorized sensory model of song to a motor program therefore involves an ongoing comparison between a "template" of song stored during the memorization phase and auditory feedback from a bird's own pro- 
duction of song: hence the description of this phase as being "sensorimotor."

In his early studies, Konishi found that once a bird of an age-limited learning species (e.g., whitecrowned sparrow) had developed crystallized song, deafening had little or no effect on the production of stable song for periods of at least 2-3 years. A different result was obtained, however, if an adult canary, an open-ended learner, was deafened. In the canary, deafening caused deficits in song structure to appear within a few weeks (Nottebohm et al., 1976; Guttinger, 1981). These and related studies suggested that there is a fundamental difference between age-limited and open-ended learning species in the dependence on auditory feedback for maintenance of crystallized song. Recent research, however, calls into question this distinction. Nordeen and Nordeen (1992) showed that previously crystallized song structure degrades within 6-8 weeks after deafening of adult zebra finches, an age-limited species. Okanoya (1991) and Woolley and Rubel (1997) found that song structure changes even more quickly in adult Bengalese finches (Lonchura striata domestica) following deafening. These observations suggest that auditory feedback may be necessary for maintenance of crystallized song even in species that do not develop new song patterns in adulthood. There may be a continuum between agelimited and open-ended learners in the dependence on auditory feedback, and the degree of song crystallization may vary among species as well.

\section{SONG CONTROL CIRCUITS}

Song behavior in songbirds is regulated by a discrete network of interconnected nuclei that undergo dramatic changes in anatomical, neurochemical, and molecular organization during periods of song learning (Nordeen and Nordeen, 1997; Alvarez-Buylla and Kirn, 1997; Clayton, 1997). Here, we will briefly discuss two pathways that are involved in song learning and production (Fig. 2) (Margoliash, 1997). A third pathway that is involved in song perception and memory will be discussed in detail elsewhere (Clayton, 1997).

The motor pathway controls the production of song, and some portion of this circuit is presumed to also participate in song learning. This circuit consists of projections from the thalamic nucleus Uva and the neostriatal nucleus NIf to the neostriatal nucleus HVc (also known as the high or higher vocal center). HVc projects to the robust nucleus of the archistriatum (RA) in the forebrain, and RA projects both to the dorsomedial part of the intercol-

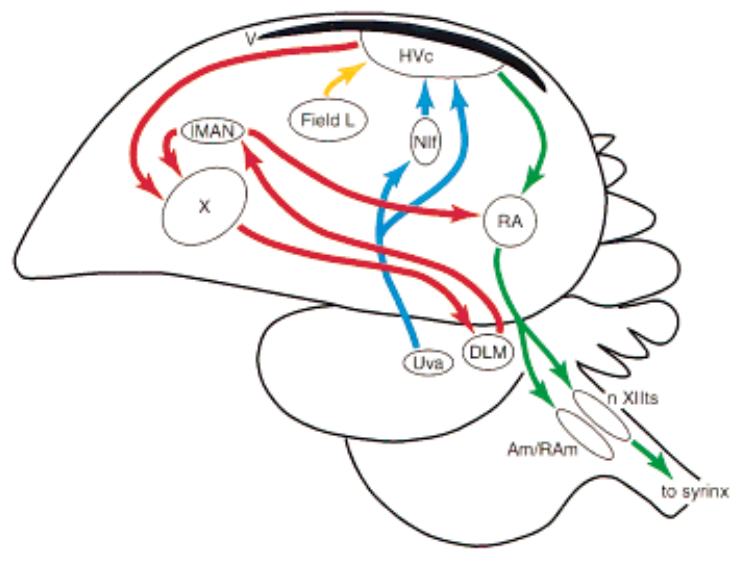

Figure 2 Schematic sagittal drawing of the songbird brain showing projections of major nuclei in the song system. The motor pathway (blue and green arrows) controls the production of song. The blue arrows indicate inputs to HVc from the thalamic nucleus Uva and the neostriatal nucleus NIf. The green arrows indicate the descending projections from $\mathrm{HVc}$ in the neostriatum to RA in the archistriatum, and thence to the vocal nucleus nXIIts, the respiratory nucleus RAm, and the laryngeal nucleus Am in the medulla. The red arrows indicate the anterior forebrain pathway that is essential for song learning. It indirectly links HVc to RA, via Area $X$ in the parolfactory lobe, DLM in the thalamus, and IMAN in the neostriatum. IMAN also projects to Area X. Field L is an auditory region in the neostriatum that projects to $\mathrm{HVc}$ (orange arrow). AM-nucleus ambiguus; DLM-medial portion of the dorsolateral nucleus of the thalamus; IMAN-lateral portion of the magnocellular nucleus of the anterior neostriatum; NIf-nucleus interface; RA-robust nucleus of the archistriatum; RAm-nucleus retroambigualis; Uva-nucleus uvaeformis; V-ventricle; X-Area X; nXIIts-tracheosyringeal part of the hypoglossal nucleus.

licular nucleus in the midbrain (not shown in Fig. 2) and to the tracheosyringeal part of the hypoglossal motor nucleus in the brain stem (nXIIts). Motor neurons in nXIIts send their axons to the muscles of the sound-producing organ, the syrinx. Neuronal activity in the premotor nuclei HVc and RA is synchronized with the production of sound by the syrinx, and the projection from RA onto the motor neurons in nXIIts is myotopically organized (Vicario, 1991; Margoliash, 1997). If nuclei in the motor pathway are inactivated, a bird may adopt appropriate posture and beak movements but does not produce song (Nottebohm et al., 1976).

The song produced by a male bird is currently the only assay of what he has learned. Given that the motor pathway is essential for song production and disruption of the pathway eliminates the ability to sing, it has been difficult to assess what role this circuit might play in either sensory acquisition or 
sensorimotor learning. Alternative ways of measuring song learning that do not depend on song production may resolve this issue.

The RA also projects to nucleus retroambigualis (RAm) and nucleus ambiguus (Am) in the medulla (Wild, 1997). RAm contains many respiratory related neurons that fire in phase with expiration. Am contains motoneurons that innervate the larynx. This pattern of descending projections from RA may be important for coordination of syringeal, respiratory, and laryngeal muscle activity during song production. Birds produce sound only during expiration, and the larynx may play a role in filtering sounds produced by the syrinx (Suthers, 1997).

The second, anterior forebrain, pathway is believed to be essential for song learning and recognition (Doupe and Solis, 1997; Margoliash, 1997). This pathway consists of projections from $\mathrm{HVc}$ to Area X, then to nucleus DLM in the thalamus, from DLM to the lateral portion of the magnocellular nucleus of the anterior neostriatum (IMAN), and finally to RA. In addition, IMAN neurons that project to RA send collaterals to Area X, thus providing the potential for feedback within this pathway. The projections within this pathway are topographically organized (reviewed by Bottjer and Johnson, 1997). Inactivation of IMAN, DLM, or Area X in adults apparently does not disrupt previously crystallized song, whereas the same lesions in juveniles prevent the development of normal song (reviewed by Bottjer et al., 1984; Sohrabji et al., 1990; Scharff and Nottebohm, 1991; Halsema and Bottjer, 1992). Juvenile males with lesions of Area X persist in producing songs that are plastic in structure, as though they are unable to crystallize. In contrast, if IMAN is lesioned in juvenile males, they produce songs with aberrant but stable structure. Data from adult canaries, which can develop new songs as adults, appear similar to data from juvenile zebra finches. Lesions of IMAN made in adult male canaries in mid-September, when song is seasonally plastic in structure, lead to a progressive decline in syllable diversity (Nottebohm et al., 1990).

There are pronounced sex differences in the nuclear size and cellular attributes of $\mathrm{HVc}, \mathrm{RA}$, and Area $X$ in species in which males sing more than females (reviewed by Arnold, 1997). The extent of morphological sex differences in the song system of a given species is closely related to the degree to which the sexes differ in song complexity (Brenowitz, 1997).

\section{HORMONE EFFECTS}

Gonadal steroid hormones and their metabolites have important effects on the song control system
(Schlinger, 1997; Bottjer and Johnson, 1997). These hormones influence the development of the song circuits (Arnold, 1997), and testosterone, or its metabolites, is necessary for crystallization of learned song. In adults, circulating steroid hormones modulate the production of song, often in a seasonal manner. Receptors for androgenic hormones are present in HVc, RA, IMAN, DM, and nXIIts. Estrogen receptors are also found in $\mathrm{HVc}$ and $\mathrm{DM}$ in several species.

\section{THE NOMENCLATURE OF HVc}

This telencephalic song nucleus was originally identified as being in the hyperstriatum, hence its designation as "hyperstriatum ventrale, pars caudale," abbreviated as HVc (Nottebohm et al., 1976). Subsequently, however, it became clear that $\mathrm{HVc}$ actually resides in the neostriatum (Paton et al., 1981). To maintain its original abbreviation, which was already widely cited in the literature, Nottebohm (1987) suggested that this nucleus be redesignated as the "high(er) vocal center," abbreviated as HVC. To avoid the functional implications of these suggested revisions, Margoliash et al. (1994) proposed that the acronym "HVc" be adopted as the proper name of this nucleus, a suggestion with which we agree. Unfortunately, however, these different designations continue to be used by different investigators, which has caused confusion among readers outside the birdsong field. Readers of this volume should be aware that these different names refer to the same nucleus.

The authors thank Karin Lent for assistance in preparing Figure 2.

\section{REFERENCES}

Alvarez-Buylla, A. and Kirn, J. R. (1997). Birth, migration, incorporation, and death of neurons in adult songbirds. J. Neurobiol. 33:585-601.

ARNOLD, A. P. (1997). Sexual differentiation of the zebra finch song system: positive evidence, negative evidence, null hypothesis, and a paradigm shift. J. Neurobiol. 33:572-584.

Bohner, J., Chaiken, M., Ball, G. F., and Marler, P. (1990). Song acquisition in photosensitive and photorefractory male European starlings. Horm. Behav. 24:582-594

Bottjer, S., Miesner, E., and Arnold, A. (1984). Forebrain lesions disrupt development but not maintenance of song in passerine birds. Science 224:901-903.

Bottjer, S. W. and Johnson, F. (1997). Circuits, hor- 
mones, and learning: vocal behavior in songbirds. $J$. Neurobiol. 33:602-618.

Brenowitz, E. A. (1997). Comparative approaches to the avian song system. J. Neurobiol. 33:517-531.

Catchpole, C. K. and Slater, P. J. B. (1995). Bird Song: Biological Themes and Variations. Cambridge University Press, Cambridge.

Chaiken, M., Bohner, J., and Marler, P. (1994). Repertoire turnover and the timing of song acquisition in European starlings. Behaviour 128:25-39.

Clayton, D. F. (1997). Role of gene regulation in song circuit development and song learning. J. Neurobiol. 33:549-571.

Doupe, A. J. and Solis, M. M. (1997). Song- and orderselective neurons develop in the songbird anterior forebrain during vocal learning. J. Neurobiol. 33:694-709.

GutTinger, H. R. (1981). Self-differentiation of song organization rules by deaf canaries. Z. Tierpsychol. 56:323-340.

Halsema, K. and BottJer, S. (1992). Chemical lesions of a thalamic nucleus disrupt song development in male zebra finches. Soc. Neurosci. Abstr. 18:1052.

KonISHI, M. (1965a). Effects of deafening on song development in American robins and black-headed grosbeaks. Z. Tierpyschol. 22:584-599.

KonISHI, M. (1965b). The role of auditory feeback in the control of vocalization in the white-crowned sparrow. Z. Tierpsychol. 22:770-783.

Kroodsma, D. E. and Miller, E. H. eds. (1996). Ecology and Evolution of Acoustic Communication in Birds. Comstock, Ithaca, NY.

Margoliash, D. (1997). Functional organization of forebrain pathways for song production and perception. J. Neurobiol. 33:671-693.

MARLER, P. (1997). Three models of song learning: evidence from behavior. J. Neurobiol. 33:501-516.

Marler, P. and Peters, S. (1987). A sensitive period for song acquisition in the song sparrow: a case of agelimited learning. Ethology 76:89-100.

Morton, E. S. (1996). A comparison of vocal behavior among tropical and temperate passerine birds. In: Ecology and Evolution of Acoustic Communication in Birds. D. E. Kroodsma and E. H. Miller, Eds. Comstock, Ithaca, NY, pp. 259-268.

NordeEn, K. and NordeEn, E. (1992). Auditory feedback is necessary for the maintenance of stereotyped song in adult zebra finches. Behav. Neural Biol. 57:58 66.

Nordeen, K. W. and Nordeen, E. J. (1997). Anatomical and synaptic substrates for avian song learning. J. Neurobiol. 33:532-548.

Nottebohm, F., Stokes, T., and Leonard, C. (1976). Central control of song in the canary. J. Comp. Neurol. 165:457-486.

Notтевонм, F. (1987). Birdsong. In: Encyclopedia of Neuroscience, Vol. I. G. Adelman, Ed. Birkhauser Boston, Boston, pp. 133-136.

Nottebohm, F., Alvarez-Buylla, A., CynX, J., Ling, C.-Y., Nottebohm, M., Suter, R., Tolles, A., and Williams, H. (1990). Song learning in birds: the relation between perception and production. Phil. Trans. R. Soc. B. 329:115-124.

Okanoya, K., Yomeda, T., Yamaguchi, A., and KIMURA, T. (1991). Acoustic communication and auditory feedback in Bengalese finches. Denshi Joho Tsushin Gakkai SP:90-100.

Paton, J. A., Manogue, K. R., and Nottebohm, F. (1981). Bilateral organization of the vocal control pathway in the budgerigar. J. Neurosci. 11:12791288.

ScharfF, C. and NotTebohm, F. (1991). A comparative study of the behavioral deficits following lesions of various parts of the zebra finch song system: implications for vocal learning. J. Neurosci. 11:2896-2913.

SCHLINGER, B. A. (1997). Sex steroids and their actions on the birdsong system. J. Neurobiol. 33:619-631.

Sohrabj, F., NordeEn, E., and NordeEn, K. (1989). Projections of androgen-accumulating neurons in a nucleus controlling avian song. Brain Res. 488:253-259.

Suthers, R. A. (1997). Peripheral control and lateralization of birdsong. J. Neurobiol. 33:632-652.

THORPE, W. H. (1958). The learning of song patterns by birds, with especial references to the song of the chaffinch, Fringilla coelebs. Ibis 100:535-570.

Thorpe, W. H. (1961). Bird Song. Cambridge University Press, Cambridge.

WILD, J. M. (1997). Neural pathways for the control of songbird production. J. Neurobiol. 33:653-670.

Woolley, S. M. N. and Rubel, E. W. (1997). Bengalese finches (Lonchura striata domestica) depend upon auditory feedback for the maintenance of adult song. $J$. Neurosci. 17:6380-6390.

VICARIO, D. (1991). Neural mechanisms of vocal production in songbirds. Curr. Opin. Neurobiol. 1:595-600. 